\title{
Female genital mutilation in Kenya: Evidence links health workers to FGM
}

Population Council

GTZ

Follow this and additional works at: https://knowledgecommons.popcouncil.org/departments_sbsr-rh

Part of the Demography, Population, and Ecology Commons, Family, Life Course, and Society

Commons, Gender and Sexuality Commons, International Public Health Commons, and the Medicine and Health Commons

How does access to this work benefit you? Let us know!

\section{Recommended Citation}

Population Council and GTZ. 2006. "Female genital mutilation in Kenya: Evidence links health workers to FGM," policy brief. Nairobi: Population Council and GTZ. 


\section{Female Genital Mutilation In Kenya}

\section{Evidence Links Health Workers to FGM}

\section{Introduction:}

Female Genital Mutilation (FGM), also referred to as Female Genital Cutting and Female Circumcision, is a traditional practice that affects women and girls in several African countries ${ }^{1}$. It is practised in a variety of ways, which the World Health Organization has classified into four broad types, all of which are found in Kenya. In some communities it is associated with passage into maturity, often forming part of an elaborate initiation ritual. In other communities, it is considered a crucial symbol of ethnic identity, and/or a religious obligation, or as a necessary pre-requisite for marriage, either through symbolising attainment of womanhood or in the case of infibulation, as a means of preserving and demonstrating virginity.

Types of FGM

WHO classifies FGM into the following:

Clitoridectomy (Type I) - partial or entire removal of the clitoris

Excision (Type II) - removal of the clitoris and the labia minora;

Infibulation (Type III) - removal of the clitoris, the labia minora and/or labia majora, and the stitching together of the raw surfaces to leave a small opening only

Unclassified (Type IV) - includes pricking, piercing, stretching or incision of the clitoris and/or labia, cauterisation of the clitoris and surrounding tissue, scraping or cutting of the vagina or surrounding tissue, introduction of corrosive substances or herbs into the vagina. community to community, and is influenced by the skills of the person doing the cutting as well the amount the child struggles. Some of the immediate complications can include:

- Injury to the adjacent tissue of urethra, vagina, perineum and rectum.

- Fracture or dislocation resulting from forceful holding down of girls and the girls struggle due to the resultant pain.

- Failure to heal as a result of wound sepsis.

Ministry of Health, 1999. National Plan of Action for the Elimination of Female Genital Mutilation in Kenya. 


\section{Long-term physical complications}

A study among women attending clinics for reproductive health services in Mali and Burkina Faso ${ }^{14}$, who had undergone different types of FGM/C, found that five percent of women in Mali and 14 percent in Burkina Faso had an observable physical complication that could be associated with FGM/C. The most frequent complications were keloids, haemorrhage, and vaginal narrowing due to scarring. The likelihood of reporting experiencing difficulty during sex and at delivery increased with the severity of cutting. Conversely, a community-based study in the Gambia ${ }^{15}$ found that physical complications such as damage to the perineum or anus, vulval tumours, and keloids, as well as painful sex, infertility, and prolapse, were no more common in women with type I or II FGM/C than in uncut women.

\section{Obstetric complications associated with FGM/C}

Antenatal complications and complications in early labour: The reduced vaginal opening affects not only delivery, but appears to be the main factor responsible for other obstetric problems. It also makes antenatal assessment, intrapartum vaginal examination or catheterisation difficult or impossible. Inadequate assessment at these times, as a result of FGM/C, may compromise the mother and foetus physically.

Prolonged labour and/or obstruction: The role of FGM/C in prolonging labour seems to depend on the quality of obstetric care rather than infibulation itself. A comparison of circumcised Sudanese immigrants with uncut Saudi women found significantly higher levels of prolonged second stage ${ }^{2}$, whereas a study of Ethiopian and Somali immigrants compared with ethnic Swedes showed no difference ${ }^{3}$.

Episiotomies and perineal tears: These are by far the commonest complications reported, with substantial evidence to show that women with FGM/C suffer more perineal injury as a result of delivery than those without FGM/C.

Pain during and after de-infibulation (anterior episiotomy) to facilitate delivery: Any extra perineal cuts incur further pain at the time when they are performed and also in the postnatal period.

Post Partum Haemorrhage (PPH) in the presence of FGM/C: Most studies describe haemorrhage following delivery in women with FGM/C type I, II or III occurring from vaginal or perineal tears/lacerations or extra cuts.

14 Jones H., N. Diop, I. Askew, and I. Kaboré. 1999. "Female genital cutting practices in Burkina Faso and Mali and their negative health outcomes," Studies in Family Planning, 30(3): 219-230. term reproductive health consequences of female genital cutting in rural Gambia: A community-based survey," Tropical Medicine and International Health, 6(7):1-11.

2 De Silva, S. “Obstetric sequelae of female circumcision”, European Journal of Obstetrics \& Gynecology and Reproductive Biology, 32: 233-240. 1989

3 Essen, B. et al. "No association between female circumcision and prolonged labour: A case control study of immigrant women giving birth in Sweden" European Journal of Obstetrics \& Gynecology and Reproductive Biology, 121: 182-185. 2005 
Maternal death postpartum attributed to FGM/C: The maternal deaths attributable to FGM/C are unattended or inappropriately treated obstructed labour caused by vulval scarring from FGM/C

Postnatal Genital Wound Infection as a complication of FGM/C: Postnatal genital wound infection as a complication of FGM/C performed earlier in life showed that the rates of infection are higher with the wound from FGM/C Type III compared to wound from type I.

\section{Gynaecological complications associated with FGM/C}

Reproductive Tract Infections and HIV: The community-based study in the Gambia ${ }^{4}$ found that women with type I or II cutting were more likely to have reproductive tract infections such as bacterial vaginosis and herpes simplex virus 2 . To date there has been no study to determine whether or not FGM/C is associated with an increased risk of acquiring HIV, either through shared sharp instruments at the time of cutting, or through the damaged tissue enhancing viral transmission. Infertility: It is unclear whether FGM/C can contribute to infertility. A review of national three DHS surveys found that women with type I or II cuts were no more likely to be infertile than uncut women ${ }^{5}$, as did a community-based survey in The Gambia $^{6}$. A study in the Sudan found that women with more severe forms of cutting, i.e. with the labia majora cut rather than the minora, were much more likely to suffer primary infertility ${ }^{7}$, but that infibulation did not make a difference.

\section{Other gynaecological complications associated with FGM/C include:}

- Difficulty in passing urine as a result of partial blockage of urinary meatus.

- Recurrent urinary and reproductive tract infections.

- Keloid scar.

- Cysts and abscesses on the vulva.

- Clitoral neuroma.

- Difficulties in menstrual flow.

- Calculus formation in the vagina.

- Vesico-vaginal fistula (VVF), recto-vaginal fistula (RVF).

\section{Psychosocial Consequences}

For some girls, genital mutilation is an occasion marked by fear, submission, inhibition and the suppression of feelings. The experience is a vivid "landmark" in their mental development, the memory of which never leaves them ${ }^{16}$. For example, a

\footnotetext{
4 Morison, L., C., Scherf, G. Ekpo, K. Paine, B. West, R. Coleman, and G. Walraven. 2001, op cit.

$5 \quad$ Larsen, U. and S. Yan. "Does female circumcision affect infertility and fertility? A study of the Central African Republic, Cote D’Ivoire, and Tanzania”, Demography 37(3):313-321. 2000.

Morison, L. et al, op cit.

Almroth, L. et al. "Primary infertility after genital mutilation in girlhood in Sudan: A case-control study”, The Lancet, 366: 365-91. 2005. 
study in Senegal found that circumcised women were significantly more likely than uncut women to have symptoms of Posttraumatic Stress Disorder, other psychiatric syndromes and memory problems. ${ }^{8}$ For example, girls have reported disturbances in their eating and sleeping habits, and in mood and cognition. As they grow older, women may develop feelings of incompleteness, loss of self-esteem, depression, chronic anxiety, phobias, panic or even psychotic disorders.

\section{Sexual complications of FGM/C}

Women who have been cut do experience sexual desires and feelings, although the physical mechanisms for sexual stimulation may be different than for women with an intact clitoris and labia. ${ }^{9}$ For example, a study in Nigeria comparing women with type I and II cuts with uncut women found no significant differences in frequency of intercourse, in arousal or in orgasm. ${ }^{10}$ For infibulated women, however, there is greater tissue removal and a reduced vaginal opening that makes penetration difficult and painful. Interviews with infibulated women and with men in Sudan indicate ways in which couples adapt their sexual behaviours to allow for this, ${ }^{11}$ but these and other studies ${ }^{12}$ give conflicting findings as to whether desire and satisfaction are diminished or not.

Women who have undergone genital mutilation may experience various forms and degrees of sexual dysfunction ${ }^{18}$. They may suffer painful sexual intercourse (dyspareunia) because of scarring, narrowing of the vaginal opening, obstruction of the vagina due to elongation of labia minora and complications such as infection.

$8 \quad$ Behrendt A. and S. Moritz. "Posttraumatic Stress Disorder and Memory Problems after Female Genital Mutilation", American Journal of Psychiatry, 162:5, 1000-1002. 2005.

$9 \quad$ See presentations made at the recent International Research Seminar on Advancing Knowledge on Psycho-Sexual Effects of FGCM/C: Assessing the Evidence organized by the International Network to Analyze, Communicate and Transform the Campaign Against FGM/C (INTACT) in Alexandria, Egypt, October 10-12, 2004. Website: http://www.intactnetwork.net/main2/document/articles/abstracts.htm.

Okonofua, F., U. Larsen, F. Oronsaye, R. Snow, and T. Slanger. 2002. "The association between female genital cutting and correlates of sexual and gynaecological morbidity in Edo State, Nigeria," British Journal of Obstetrics and Gynaecology, 109(10): 1089-96.

$11 \quad$ Lightfoot-Klein H. 1989. "The sexual experience and marital adjustment of genitally circumcised and infibulated females in the Sudan," Journal of Sex Research, 26(3): 375-392; Almroth L., V. AlmrothBerffren, O. Hassanein, S. Al-Said, S. Hasan, U-B. Lithell, and S. Bergstrom. 2001. "Male Complications of Female Genital Mutilation," Social Sciences and Medicine, 53: 1455-1460; Gruenbaum, E. 2004. "Sexual response and Sudanese conceptions of the infibulated and uninfibulated vulva: research in Sudan, 2004,'Paper presented at the Seminar on Advancing Knowledge on PsychoSexual Effects of FGCM/C: Assessing the Evidence. Cairo: INTACT. its Psychosexual Impact," Journal of Sexual Marital Therapy, 27(2): 465-473. 
According to a study in Sudan ${ }^{20}$, some men who are married to infibulated women have reported undergoing complications including development of skin wounds, bleeding or inflammation of the penis, difficulties with penetration and the associated psychological problems, and decreased sexual desire and enjoyment by the woman.

\section{Potential Complications with the Foetus}

Almost all cases of foetal death appear to be related to an obstruction to delivery caused by vulval scarring. A study in Norway found that perinatal complications (e.g. foetal distress, low Apgar scores and pre-labour deaths) were two to three times more frequent among Somali migrant women who had been infibulated than among ethnic Norwegians ${ }^{25}$. A study comparing uncut Saudi Arabian women with infibulated Sudanese immigrants also found significantly higher levels of neonatal distress ${ }^{26}$. A study in Kenya ${ }^{27}$ found that women with Type II and III cutting had an increased risk of having a caesarean section, and of perinatal death. The health-seeking behaviour and conditions under which women experience labour and delivery are important determinants of whether foetal morbidity and deaths can be attributed directly to infibulation; infibulated women delivering in high quality settings, as found in Europe, are no more likely to have foetal complications than uncut women ${ }^{13}$.

\begin{tabular}{lc}
\hline Ethnic group & $\begin{array}{c}\text { \% women } \\
\text { circumcised }\end{array}$ \\
\hline Somali & 97 \\
\hline Abagusii & 96 \\
\hline Maasai & 94 \\
\hline Taita Taveta & 62 \\
\hline Kalenjin & 49 \\
\hline Embu & 43 \\
\hline Meru & 41 \\
\hline Kikuyu & 33 \\
\hline Kamba & 27 \\
\hline Other & 21 \\
\hline Mijikenda/Swahili & 5 \\
\hline Luhya & 1 \\
\hline Luo & 1 \\
\hline
\end{tabular}

20 Almroth L. et al. "Male complications of female genital mutilation", Social Science and Medicine, 53 1455-1460. 2001.

25 Vangen S., C. Stoltenberg, R. Johansen, J. Sundby, and B. Stray-Pedersen. 2002. "Perinatal complication among ethnic Somalis in Norway," Acta Obstetricia et Gynecologica Scandinavica, $81: 317-22$.

De Silva, S. op cit.

Karanja, J. and G. Jaldesa: WHO study on obstetric sequelae of FGM (initial results presented at a conference in Kenya, December 2004)

Essén, B., B. Bödker, N. Sjöberg, S. Gudmundsson, P. Östegen, and J. Langhoff-Roos. 2002. "Is there an association between female circumcision and perinatal death?" Bulletin of the World Health Organization, 80: 629-632; Vangen, S., R. Johansen, J. Sundby, B. Træen, and B. Stray-Pedersen. 2004. "Qualitative study of perinatal experiences among Somali women and local healthcare professionals in Norway," European Journal of Obstetrics \& Gynecology and Reproductive Biology, 112: 29-35. 


\section{How widespread is the practice in Kenya?}

- FGC is practiced in over half of the districts in Kenya.

- Thirty-two per cent of all women aged 15-49 years surveyed in the 2003 Kenya Demographic and Health Survey reported being cut, which is a decline from $38 \%$ recorded in the 1998 KDHS.

- The practice is nearly universal among the Somali, Abagusii, and Masaai.

- The practise appears to be declining substantially among the younger generation, with nearly one-half of women aged 35 years and above being cut, but only 26 percent of those age 15-19 years. This decrease is particularly pronounced among the Kalenjin (62\% to $49 \%$ ), Kikuyu (43\% to $33 \%$ ) and Kamba (33\% to $27 \%$ ).

- Different ethnic groups also practice different types of circumcision. While clitoridectomy (type I) and excision (type II) are the predominant types in the country, the Somali, Borana, Rendille, and Samburu practice the more severe form of infibulation (type III). There is evidence that among the Abagusii, there is an increasing trend towards nicking the skin around the clitoris (type IV) ${ }^{14}$.

\section{What are communities' reasons for continuing to practise FGM?}

Research studies have uncovered several reasons why communities continue to practice FGM:

- It is considered a necessary rite of passage into adulthood for the young girl among the Meru, Masaai and Kikuyu.

- It is a means for ethnic identity: for example, among the Abagusii, it is used to distinguish her from neighbouring non-circumcising communities ${ }^{15}$.

- It is thought to increase a woman's marriageability: the majority of those that circumcise among the Meru do so to increase marriage prospects for daughters ${ }^{16}$, and among the Masaai in Kajiado ${ }^{17}$ girls are circumcised to prepare them for marriage, which follows almost immediately, and is a source of income (dowry) for their family.

14 Njue C. and I. Askew. 2004. Medicalization of Female Genital Cutting Among the Abagusii in Nyanza Province, Kenya, FRONTIERS Final Report. Nairobi, Kenya: Population Council.

Njue, C and I. Askew op. cit.

Chege, J.N., I. Askew, \& J. Liku. 2001. An Assessment of the Alternative Rites Approach for Encouraging Abandonment of Female Genital Mutilation in Kenya. Population Council, Frontiers in Reproductive Health Study Report. 
- Preservation of sexual purity before marriage, and maintaining absolute monogamy within marriage: these are highly valued in the Somali community where infibulation is used to enforce these values, besides the perceived obligation of a Muslim woman to be circumcised ${ }^{18}$.

\section{Are medical practitioners involved in the practice?}

There is evidence from several studies to confirm that medical practitioners and other health facility staff are involved in perpetuating FGM in Kenya. In particular, the Abagusii and the Somali ethnic groups appear to be increasingly requesting medical practitioners to undertake the cutting. Data from research studies show:

- In the $1998 \mathrm{KDHS}$, one-third of all cut women reported having been cut by a health worker, and this proportion was as high as one half of all cut Abagusii.

- A study among the Abagusii ${ }^{19}$ found that preference for medical staff has increased recently - whereas $94 \%$ of circumcised mothers had been cut by a traditional circumciser, $71 \%$ of girls aged $4-17$ years had been cut by a nurse or doctor. Moreover, only two percent of the mothers had been cut at a health facility, whereas $37 \%$ of the girls reported being cut at a health facility.

- A study ${ }^{20}$ among health workers who serve the Somali community found that three of the 18 interviewed in North Eastern Province and 15 of 26 in Nairobi reported having been approached to perform FGC.

- Recent studies by GTZ ${ }^{21}$ indicate that the proportions reporting being cut by health workers are: Kuria, 10\%; Kajiado 10\%; Meru North 3\%; and Tharaka $2 \%$. Traditional birth attendants also reported using surgical scalpels and gloves procured from local pharmacies when cutting girls, indicating further medicalization.

Medical staff working among the Somali community appear also to be involved in re-infibulating women after delivery ${ }^{22}$; many nurse and midwives reported that, following delivery, they were sometimes requested by the woman to re-stitch her vulva so as to re-create the reduced opening. Of 57 antenatal clients interviewed, 35 reported being re-infibulated following a previous pregnancy, 26 by a nurse or midwife and seven by a TBA (the other two did not specify who did it). WHO expressly advises against as it is considered to be a perpetuation of FGM.

\footnotetext{
18 Jaldesa et al, op cit.

19 Chege et al, op cit

$20 \quad$ Jaldesa et al, op cit.

21 Ministry of Health/GTZ.FGM Project (op cit);

22 Jaldesa et al, op cit.
} 
What can the MOH do to reduce the practice and its adverse effects?

FGM contravenes several basic rights of women and girls. The United Nations Convention on the Rights of the Child, and the Maputo Protocol of the African Union recognise FGM as a violation of a girl child's basic human rights. FGM also contravenes a woman's human right to bodily integrity. FGM is also associated with social practices and values that undermine the welfare of women and girls, such as early marriage, and discontinuation of school education.

Kenya has a long history of vigorous efforts to encourage the abandonment of FGM, dating back to the 1930s' efforts by the colonial administration and Christian missionaries. Anti-FGC campaigns have employed various strategies, including alternative rites of passage for adolescent girls, empowerment of the girl child, public education campaigns, promotion of the girl child education, and advocacy programs for women and girls. The government has passed legislation outlawing the practice (the Children's Act 2001), and key figures have made public pronouncements against the practice, while the mass media has increased its coverage of the practice.

In 1999, the Ministry of Health $(\mathrm{MOH})$ launched a National Plan of Action for the Elimination of Female Genital Mutilation in Kenya and in 2001, it circulated a policy directive making FGC illegal in all health facilities. The objectives of the National Plan of Action (NPA) include reducing the proportion of women and girls who undergo FGM in Kenya; increasing the proportion of communities that support the eradication of FGM; increasing the proportion of healthcare facilities that provide care, counselling and support to girls and woman affected by FGM; and increasing the technical and advocacy capacity of institutions and communities to develop and manage FGM eradication programs.

To achieve this, the NAP proposes five broad strategies: the establishment of national and district FGM program co-ordination committees; the establishment of a multi-sectoral collaboration to ensure integration of anti-FGM interventions in key development programs; mapping of new and on-going interventions on FGM; coordination of new and on-going FGM interventions; and establishment of proactive mechanisms for resource mobilization and allocation to the FGM elimination program. The NPA has been widely disseminated in the country, and some districts have already set up FGM co-ordination committees.

However, the practice continues. Several recommendations can be made, which may accelerate abandonment of this practice and which would strengthen the role of the Ministry of Health in managing the complications among those already cut: 
- Strengthen supervision in those districts where it is known that health workers are involved in genital cutting and re-infibulation. The $\mathrm{MOH}$ needs to develop and enforce guidelines for district supervisors on appropriate actions to deter their staff from engaging in the practice.

- Disseminate the $\mathrm{MOH}^{\prime}$ s policy against health workers practising FGC, and ensure that all health staff understand that FGM contravenes the law.

- Include a component on FGM in pre-service training, to educate nurses and other medical staff in identifying the different types of cutting, recognising complications that may be associated with cutting and their management, and understanding the socio-cultural factors that drive the practice.

- Provide training to its clinical staff in the medical management of gynaecological complications associated with FGM, especially the more severe forms. Train and equip providers working among populations that practice infibulation to safely provide de-infibulation, ${ }^{23}$ and assist them to offer this service at the time of marriage, during antenatal visits, or during the second stage of labour.

- Train nurses providing antenatal care to infibulated women in counselling about the likelihood and types of problems that may occur during delivery, and the need to have the baby at a health facility to minimise these risks. Such counselling should also include information on de-infibulation and should discourage requests for re-infibulation.

- Build the capacity of health staff and facilities that handle deliveries among infibulated women, to provide an optimum quality of care needed to handle complications associated with infibulation. This could include de-infibulation, correct management of obstructed labour, perineal tears, and postpartum haemorrhage, including episiotomy and caesarean section. It would also include handling birth asphyxia, and being aware of the increased likelihood of perinatal death. The $\mathrm{MOH}$ also needs to provide the equipment needed to handle these complications.

- Provide facilities for surgical reconstruction to repair anatomical damages arising from the severe form s of FGC.

- Build the capacity of health workers to advocate against the practice during routine consultations for primary health care and during community outreach activities. 
- Establish a monitoring and evaluation system to track the process of implementation of the NPA.

In addition, the $\mathrm{MOH}$ could work closely with the medical professional associations and regulatory bodies, including the National Nursing Council, to enforce measures to curb the involvement of health facility staff in FGC. The MOH can also support other key efforts for the abandonment of FGC by:

- Supporting punitive measures against those caught practicing FGC. Local administration personnel (such as police, chiefs, Children's Officers, and social workers) should actively pursue those known to be involved and to close health facilities that carry out the practice.

- Implementing community-wide approaches that present FGC not just as a health issue but also as a practice that subjugates women and violates their rights to bodily integrity. Such an approach should include all stakeholders, political, religious, cultural leadership, and involve women and girls as well as men and boys. The involvement of men is particularly important, as its is their overall dominance in society that has led to women supporting FGC as a means of gaining social identity and access to resources. 
This briefing paper was jointly produced by the FRONTIERS in Reproductive Health Programme of the Population Council, with the support of the United States Agency of International Development (USAID), and the Reproductive Health Programme of GTZ Kenya.

For further information, contact:

Ian Askew, FRONTIERS Program, Tel 2713480, Nairobi;

E-mail: iaskew@pcnairobi.org

or

Jane Kamau, Anti-FGM Program, GTZ Kenya, Tel 2721187;

E-mail:fgm@gtzkenyahealth.com
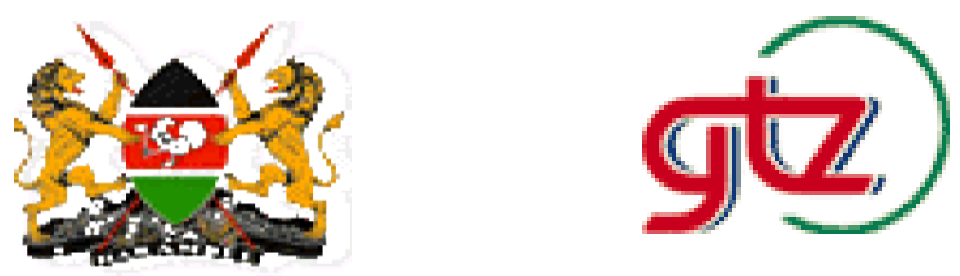